\title{
Expression of MMP-9 and -13 on the Pressure Side under Orthodontic Loading
}

\author{
Su-Jung Mah1, Yoonjung Lee², Youn-Sic Chun², Won Hee Lim ${ }^{3 *}$ \\ ${ }^{1}$ Department of Orthodontics, Kyung Hee University Hospital at Gangdong, Seoul, South Korea \\ ${ }^{2}$ Division of Orthodontics, Ewha Womans' University Mokdong Hospital, Seoul, South Korea \\ ${ }^{3}$ Department of Orthodontics, School of Dentistry \& Dental Research Institute, Seoul National University, Seoul, \\ South Korea \\ Email: *wonheelim@gmail.com
}

Received 1 June 2014; revised 18 July 2014; accepted 31 July 2014

Copyright (C) 2014 by authors and Scientific Research Publishing Inc.

This work is licensed under the Creative Commons Attribution International License (CC BY).

http://creativecommons.org/licenses/by/4.0/

c) (i) Open Access

\begin{abstract}
Purpose: The purpose of this study was to investigate the expression of MMP-9 and MMP-13 on compression side of tooth movement. Material and Methods: Twenty male Wistar rats were used for this experiment. Maxillary right first molar was moved orthodontically with a constant force of $20 \mathrm{~g}$ and on the side of the maxillary left first molar was used as control group. On the 4th, 10th and 17 th days after experiment, 5 rats were euthanized, respectively. Histologic process was processed for immunohistochemical staining of MMP-9 and -13. Results: MMP-9 and -13 expressions were upregulated at day 4 after tooth movement. The expression of MMP-9 was not observed at days 7, 10 and 14, while the expression of MMP-13 was greatly increased at days 7 and 10. Conclusion: This study suggests that different characteristics of MMPs expression may contribute to the remodeling process of collagen fibers in the PDL during tooth movement.
\end{abstract}

\section{Keywords}

Component, Tooth Movement, Pressure Side, MMP-9, MMP-13

\section{Introduction}

Orthodontic tooth movement occurs from combined biological reactions to orthodontic force in the periodontal ligament (PDL) and alveolar bone [1] [2]. Many studies have been performed to investigate the reaction of alveolar bone, however, less is known about the PDL remodeling during tooth movement. The periodontal ligament originates from cranial neural crest cells that differentiate into the collagen-producing cells in the peri-

*Corresponding author. 
odontal ligament [3]. The cells in the PDL secrete an extracellular matrix that organizes collagen fiber bundles. The PDL width is maintained throughout a life time, which is the measure of the homeostasis [4]. This is achieved by adaptation of the PDL to applied forces. The cells in PDL play an important role in this remodeling process.

During tooth movement, the cells in the PDL play an important role in the remodeling process to adapt into the new position. Force loading causes recruitment of inflammatory cells, which are detected in the crevicular fluid as well as PDL during orthodontic tooth movement [5]-[7]. On pressure side, bone remodeling occurs by osteoclasts and collagen fiber remodeling occurs by fibroblasts in the PDL cells. Proteinases produced by PDL cells may participate in phagocytes is during the remodeling of collagen fibers [8] [9]. Matrix metalloproteinases (MMPs) are zinc-dependant protease involved in inflammation, degenerative diseases and wound healing [10] [11]. MMPs are involved in the breakdown of matrix in embryonic development, bone development and wound healing. Most MMPs, which are secreted as an inactive form, are activated when chopped by other extracellular proteinases. MMP-9 degrades type IV and V collagens and other matrix proteins [12]. MMP-13 cleaves type II collagen more efficiently compared to types I and III [13]. MMP-13 expression is increased during embryonic development, which is involved in reorganization of the collagen [14]. Some subgroups of MMP including MMP-8, -9 and -13 are highly expressed under inflammation such as rheumatoid arthritis and osteoarthritis [15] [16]. In addition, MMP-8, -9 and -13 expressions were found in the PDL after tooth movement. Thus, these MMPs could play an important role in the remodeling process of the PDL. The aim of this study is to test the hypothesis that MMP-9 and -13 are expressed on the pressure sides during tooth movement using mouse model.

\section{Material and Methods}

\subsection{Experiment}

Twenty 26-week-old, male Wistar rats, approximate weight of 260 g, from Seoul University vivarium were used. All animals were kept in stainless-steel cages in air-conditioning and subject to standard 12-hour light/dark cycle. They were checked everyday in regard to their health status. This experiment was approved by the ethics committee of Seoul National University.

A constant force of $20 \mathrm{~g}$ was generated using a closed coil spring (Sentalloy, $0.009 \times 0.036$, Tomy Incorporated, Tokyo, Japan) to move the maxillary first molar mesially. The springs were attached to the maxillary right first molar and the maxillary incisors using a stainless steel ligature wires. Light-curing bonding material ( $3 \mathrm{M}$ Unitek, Nonrovia, CA, USA) was applied on perforations produced by diamond bur along the mesio-lingual and disto-lingual line angle of the maxillary first molar and the distal sides of the incisors to ensure maximum retention of the coil spring (Figure 1). Reactivation was not done during the study period. The side of the maxillary left first molar was used as a control.

All procedures were performed using general anesthesia induced by subcutaneous injections of Zoletil (Tiletamine 125 ml, Zolazepam 125 ml; 0.04 ml Virbac, 060516 carros, France) and Rompun (Xylazirehydroxychloride

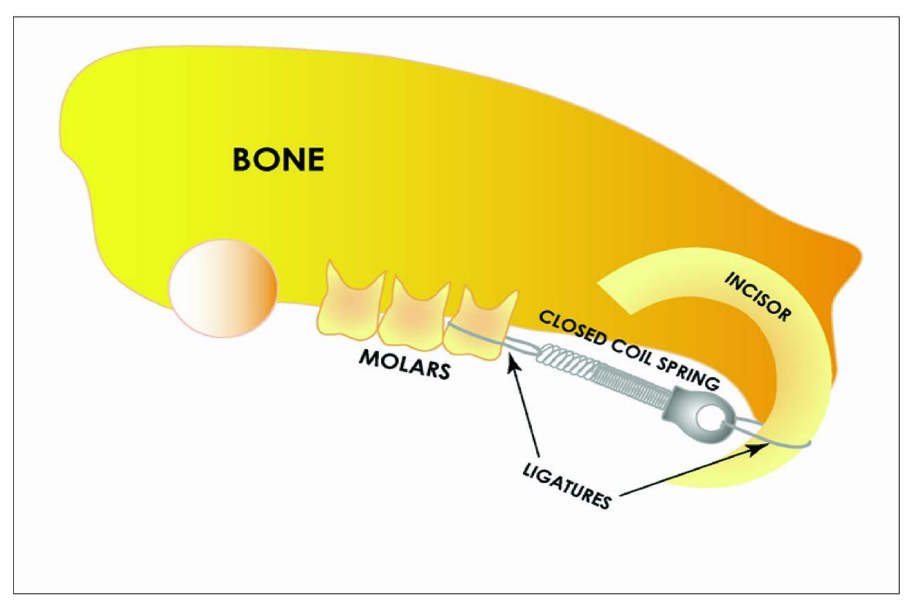

Figure 1. Schematic drawing of the rat model showed the placement of orthodontic appliance. 
$23.32 \mathrm{mg} / \mathrm{ml}$; $0.01 \mathrm{ml}$ Bayer AG, 51368 Leverkusen, German). At the end of each experimental period the animals were euthanized using an overdose of an anesthetic.

\subsection{Sample Preparation, Processing and Histology}

Maxillae from mice were harvested and fixed in $4 \%$ paraformaldehyde overnight at $4{ }^{\circ} \mathrm{C}$. Samples were decalcified in a heat-controlled microwave in 19\% EDTA for two weeks. After demineralization, specimens were dehydrated through an ascending ethanol series prior to paraffin embedding. Eight-micron-thick longitudinal sections were cut and collected on Superfrost-plus slides for histology. Hematoxylin and eosin stain (H \& E) stain was performed to see the overall structures.

\subsection{Immunohistochemistry}

Tissue sections were deparaffinized following standard procedures. Endogenous peroxidase activity was quenched by 3\% hydrogen peroxide for $5 \mathrm{~min}$, and then washed in PBS. Slides were blocked with $5 \%$ goat serum (Vector S-1000) for 1 hour at room temperature. The appropriate primary antibody was added and incubated overnight at $4^{\circ} \mathrm{C}$, then washed in PBS. Samples were incubated with appropriate biotinylated secondary antibodies (Vector BA-x) for 30 minutes, and washed in PBS. An advidin/biotinylated enzyme complex (Kit ABC Peroxidase Standard Vectastain PK-4000) was added and incubated for 30 minutes and a DAB substrate kit (Kit Vector Peroxidase subtrate DAB SK-4100) was used to develop the color reaction. Antibodies used include MMP-9 (Epitomics, Burlingame, CA) and MMP-13 (Abcam, Cambridge, MA). All immunohistochemical staining was performed at the same time using the same concentration of antibody and for the same duration. Each assay was run in triplicate.

\section{Results}

\subsection{Histologic Evaluation in the PDL}

In control group, the PDL is located between alveolar bone and root. The difference of the PDL width between tension and pressure side was not observed in the control group (Figure 2(A)). Surprising, root resorption close to cementoenamel junction was observed in the sections of control groups (Figure 2(A)). In the experimental groups, the PDL width was widened on the tension side compared to the pressure side and collagen fibers appeared elongated on the tension side on day 4 after tooth movement (Figure 2(B)). On day 7 following tooth movement, the difference of the PDL width between tension and pressure sides was not evident (Figure 2(C)). On days 10 and 17 after tooth movement, the PDL width was similar between tension and pressure sides (Figure 2(D) and Figure 2(E)).

\subsection{Expression Pattern of MMP-9}

MMP-9 expression was not observed in both the cells lining the cementum and alveolar bone of the control groups (Figures 3(A)-(D)). On the other hand, the expression of MMP-9 in the PDL space was minimally observed on day 4 after tooth movement (Figure 3(E)). The expression of MMP-9 in the PDL was observed on day 7 (Figure 3(F)) after tooth movement. However, expression of MMP-9 returned to the control group on days 10 and 17 after tooth movement (Figure 3(G) and Figure 3(H)).
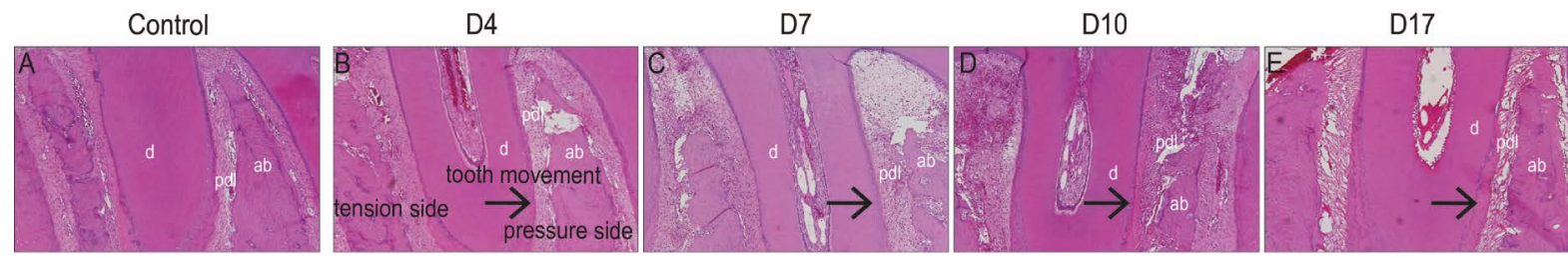

Figure 2. (A) The control group showed no difference in the PDL width between the tension and pressure sides; (B) The experiment group showed the widen PDL width on the tension side compared to the pressure side on day 4 after tooth movement; (C) The PDL width between tension and pressure sides showed no big difference on day 7 after tooth movement; (D) The PDL width between tension and pressure sides appeared to be similar on day 10; (E) on day 17 after tooth movement. 


\subsection{Expression Pattern of MMP-13}

MMP-13 was expressed in neither the cells lining the cementum and alveolar bone of the control groups (Figures 4(A)-(D)). On the other hand, the experimental group showed the expression of MMP-13 in the PDL space on day 4 after tooth movement (Figure 4(E)). MMP-13 was expressed throughout the PDL space in the experimental group. The expression of MMP-13 in the PDL was maintained on day 7 (Figure 4(F)) and day 10 (Figure 4(G)) after tooth movement. On the other hand, on day 17 after tooth movement, expression of MMP-13 was decreased (Figure $4(\mathbf{H})$ ) compared to days 4,7 , and 10, which returned to the control group. Root resoprtion was also observed in the specimen of day 17 after tooth movement.

\section{Discussion}

The width of PDL is changed depending on the application of force during tooth movement. On the pressure side, the width of PDL is smaller than that of tension side due to the status of collagen fibers in the PDL. Collagen fibers on the tension side are elongated, while those on the pressure side are compressed. In histologic views, the differences in the PDL width between tension and pressure sides are evident at day 4 after tooth movement. As time goes, the differences in the PDL width between tension and pressure sides are invisible. It is partly because the activation of tooth movement was not performed after placement of the closed coil spring.

During tooth movement, the collagen fibers in the PDL are remodeled by proteases. Among MMPs, MMP-1, 8, 9 and 13 are considered enzymes working in the PDL. In the present study, MMP-9 and -13 were not expressed on the pressure side of the control PDL. MMP-9 was not expressed in the healthy PDL cells [15], while

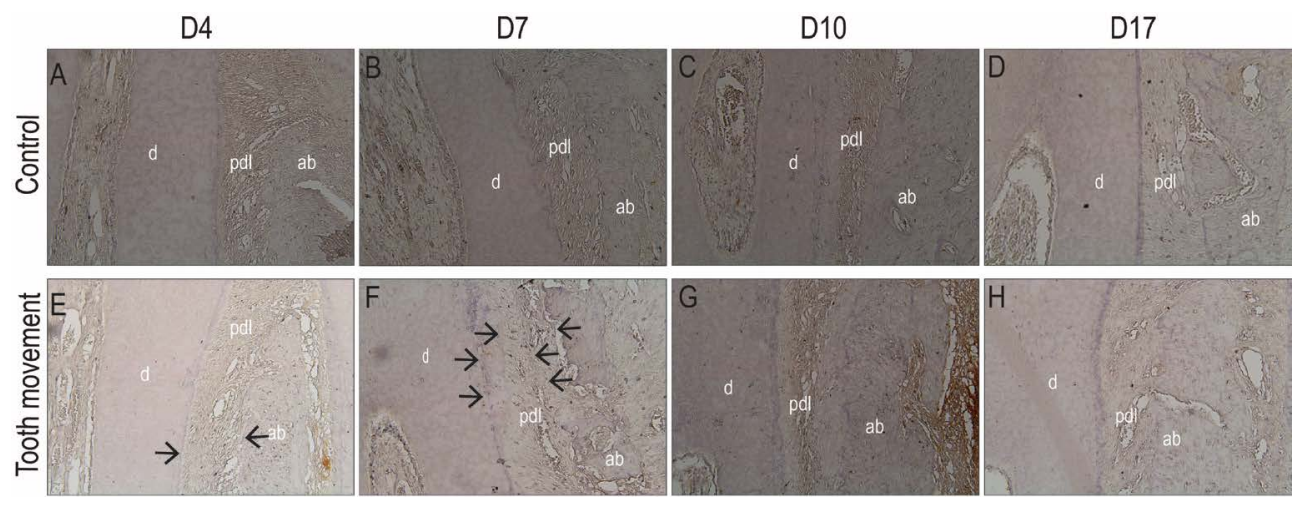

Figure 3. (A)-(D) The control side showed no expression of MMP-9; (E) The minimal expression of MMP-9 was observed on the experimental group at day 4 after tooth movement; (F) The expression of MMP-9 was increased at day 7 after tooth movement; (G) Expression of MMP-9 appeared to be similar with the control group at days 10 and $17 ;(\mathrm{H})$ after tooth movement.

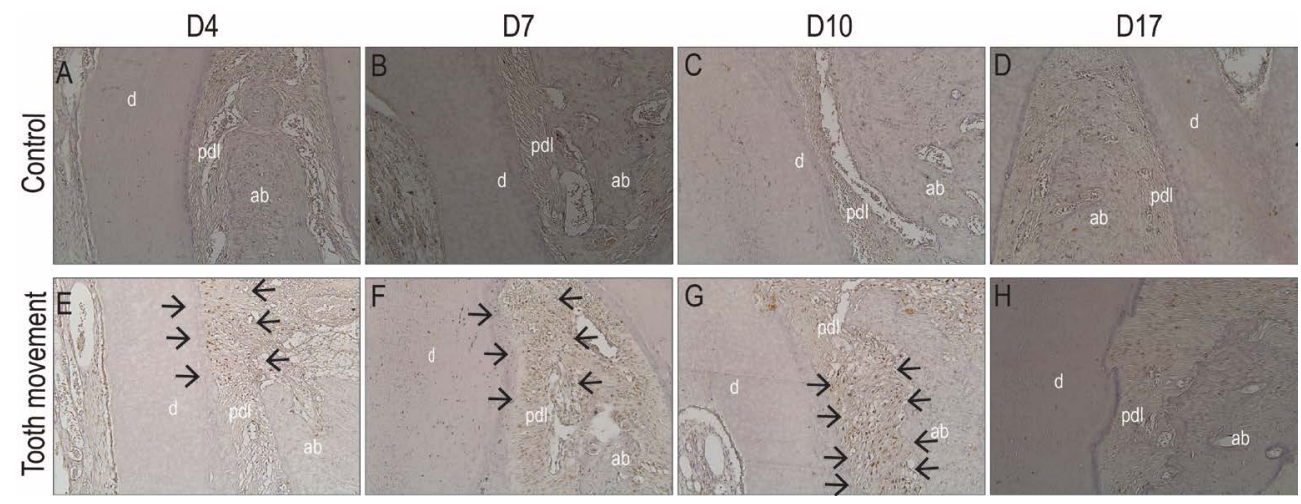

Figure 4. (A)-(D) The control side showed no expression of MMP-13; (E) The expression of MMP-13 throughout the PDL space was observed on day 4 after tooth movement; (F) The expression of MMP-13 was maintained on day 7 and day 10; (G) after tooth movement; $(\mathrm{H})$ The expression of MMP-13 returned to the control group at day 17 after tooth movement. 
MMP-13 expression was expression in a low level [17]. In normal physiologic condition, the PDL may be under the process of remodeling and collagen matrix in the PDL may be degraded by MMPs. Aging affects the expression of MMPs in the PDL [18], so low level of MMP-13 may be related to aged animals in this study.

The experimental group showed expression of MMP-9 at day 4 after tooth movement. The expression of MMP-9 decreased with time and no expression was observed afterwards. From this observation, it can be interpreted that MMP-9 was expressed during early period of tooth movement. Thus, it appeared that MMP-9 may participate in early remodeling process of collagen fibers in the PDL. Expression of MMP-13 was detected at day 4 and maintained until day 10 after tooth movement. The upregulation of MMP-13 was predominant compared to that of MMP-9. Collagen matrix in the PDL may be degraded by MMPs, but the distribution of MMP-13 was not restricted on either cementum side or alveolar bone side. MMP-13 was observed throughout the PDL space, so other MMPs may contribute to degrade collagens close to cementum and alveolar bone. In addition, expressions of MMP-9 and -13 were in the transient nature. During tooth movement, the PDL cells under mechanical forces produce Interleukin-1 and prostaglandins (PG) [19] [20], which induce MMPs [21] [22]. This indirect regulation of MMPs for collagen fibers remodeling appeared to be similar with bone remodeling. Under pressure induced by mechanical force, PG in the PDL cells activates the expression of the receptor activator of nuclear factor kappa, which results in osteoclastogenesis. Thus, remodeling of collagen fibers and bone is regulated in the indirect way. Further studies using different age groups can provide more information related to collagen remodeling, which will show the role of collagen during tooth movement. In addition, increased number of animals can provide the quantitative analyses for expressions of MMP-9 and -13 bases on the result of this preliminary study.

\section{Conclusion}

The present study showed MMP-9 and -13 expressions on the pressure side after tooth movement. The expression of MMP-9 and -13 showed the different characteristics under compressive forces. Further studies are needed to investigate the mechanism related to PG, IL-1s and MMPs for better understanding of biology during tooth movement.

\section{Acknowledgements}

This work was supported by a grant no. 04-2009-0037 from the Seoul National University Dental Hospital Research Fund.

\section{References}

[1] Krishnan, V. and Davidovitch, Z. (2006) Cellular, Molecular, and Tissue-Level Reactions to Orthodontic Force. American Journal of Orthodontics and Dentofacial Orthopedics, 129, 469.e1-469.e32.

[2] Masella, R.S. and Meister, M. (2006) Current Concepts in the Biology of Orthodontic Tooth Movement. American Journal of Orthodontics and Dentofacial Orthopedics, 129, 458-468. http://dx.doi.org/10.1016/j.ajodo.2005.12.013

[3] Palmer, R.M. and Lubbock, M.J. (1995) The Soft Connective Tissues of the Gingiva and Periodontal Ligament: Are They Unique? Oral Diseases, 1, 230-237. http://dx.doi.org/10.1111/j.1601-0825.1995.tb00188.x

[4] McCulloch, C.A., Lekic, P. and McKee, M.D. (2000) Role of Physical Forces in Regulating the Form and Function of the Periodontal Ligament. Periodontology, 24, 56-72. http://dx.doi.org/10.1034/j.1600-0757.2000.2240104.X

[5] Marcaccini, A.M., Amato, P.A., Leao, F.V., Gerlach, R.F. and Ferreira, J.T. (2010) Myeloperoxidase Activity Is Increased in Gingival Crevicular Fluid and Whole Saliva after Fixed Orthodontic Appliance Activation. American Journal of Orthodontics and Dentofacial Orthopedics, 138, 613-616. http://dx.doi.org/10.1016/j.ajodo.2010.01.029

[6] Ingman, T., Apajalahti, S., Mantyla, P., Savolainen, P. and Sorsa, T. (2005) Matrix Metalloproteinase-1 and -8 in Gingival Crevicular Fluid during Orthodontic Tooth Movement: A Pilot Study during 1 Month of Follow-Up after Fixed Appliance Activation. European Journal of Orthodontics, 27, 202-207. http://dx.doi.org/10.1093/ejo/cjh097

[7] Apajalahti, S., Sorsa, T., Railavo, S. and Ingman, T. (2003) The in Vivo Levels of Matrix Metalloproteinase-1 and -8 in Gingival Crevicular Fluid during Initial Orthodontic Tooth Movement. Journal of Dental Research, 82, 1018-1022. http://dx.doi.org/10.1177/154405910308201216

[8] Bolcato-Bellemin, A.L., Elkaim, R., Abehsera, A., Fausser, J.L., Haikel, Y. and Tenenbaum, H. (2000) Expression of mRNAs Encoding for Alpha and Beta Integrin Subunits, MMPs, and TIMPs in Stretched Human Periodontal Ligament and Gingival Fibroblasts. Journal of Dental Research, 79, 1712-1716. 
http://dx.doi.org/10.1177/00220345000790091201

[9] Nakaya, H., Oates, T.W., Hoang, A.M., Kamoi, K. and Cochran, D.L. (1997) Effects of Interleukin-1 Beta on Matrix Metalloproteinase-3 Levels in Human Periodontal Ligament Cells. Journal of Periodontology, 68, 517-523. http://dx.doi.org/10.1902/jop.1997.68.6.517

[10] Bartlett, J.D. and Smith, C.E. (2013) Modulation of Cell-Cell Junctional Complexes by Matrix Metalloproteinases. Journal of Dental Research, 92, 10-17. http://dx.doi.org/10.1177/0022034512463397

[11] Holliday, L.S., Ostrov, D.A., Wronski, T.J. and Dolce, C. (2009) Osteoclast Polarization and Orthodontic Tooth Movement. Orthodontics \& Craniofacial Research, 12, 105-112. http://dx.doi.org/10.1111/j.1601-6343.2009.01443.x

[12] O’Sullivan, S., Medina, C., Ledwidge, M., Radomski, M.W. and Gilmer, J.F. (2014) Nitric Oxide-Matrix Metaloproteinase-9 Interactions: Biological and Pharmacological Significance: NO and MMP-9 Interactions. Biochimica et Biophysica Acta, 1843, 603-617. http://dx.doi.org/10.1016/j.bbamcr.2013.12.006

[13] Leeman, M.F., Curran, S. and Murray, G.I. (2002) The Structure, Regulation, and Function of Human Matrix Metalloproteinase-13. Critical Reviews in Biochemistry and Molecular Biology, 37, 149-166. http://dx.doi.org/10.1080/10409230290771483

[14] Hellingman, C.A., Koevoet, W. and van Osch, G.J. (2012) Can One Generate Stable Hyaline Cartilage from Adult Mesenchymal Stem Cells? A Developmental Approach. Journal of Tissue Engineering and Regenerative Medicine, 6, e1-e11. http://dx.doi.org/10.1002/term.502

[15] El-Awady, A.R., Lapp, C.A., Gamal, A.Y., Sharawy, M.M., Wenger, K.H., Cutler, C.W. and Messer, R.L.W. (2013) Human Periodontal Ligament Fibroblast Responses to Compression in Chronic Periodontitis. Journal of Clinical Periodontology, 40, 661-671. http://dx.doi.org/10.1111/jcpe.12100

[16] Takahashi, I., Nishimura, M., Onodera, K., Bae, J.W., Mitani, H., Okazaki, M., Sasano, Y. and Mitani, H. (2003) Expression of MMP-8 and MMP-13 Genes in the Periodontal Ligament during Tooth Movement in Rats. Journal of Dental Research, 82, 646-651. http://dx.doi.org/10.1177/154405910308200815

[17] Proff, P., Reicheneder, C., Faltermeier, A., Kubein-Meesenburg, D. and Romer, P. (2014) Effects of Mechanical and Bacterial Stressors on Cytokine and Growth-Factor Expression in Periodontal Ligament Cells. Journal of Orofacial Orthopedics = Fortschritte der Kieferorthopadie: Organ/Official Journal Deutsche Gesellschaft fur Kieferorthopadie, 75, 191-202.

[18] Benatti, B.B., Silverio, K.G., Casati, M.Z., Sallum, E.A. and Nociti Jr., F.H. (2008) Influence of Aging on Biological Properties of Periodontal Ligament Cells. Connective Tissue Research, 49, 401-408. http://dx.doi.org/10.1080/03008200802171159

[19] Long, P., Liu, F., Piesco, N.P., Kapur, R. and Agarwal, S. (2002) Signaling by Mechanical Strain Involves Transcriptional Regulation of Proinflammatory Genes in Human Periodontal Ligament Cells in Vitro. Bone, 30, 547-552. http://dx.doi.org/10.1016/S8756-3282(02)00673-7

[20] Kanzaki, H., Chiba, M., Shimizu, Y. and Mitani, H. (2002) Periodontal Ligament Cells under Mechanical Stress Induce Osteoclastogenesis by Receptor Activator of Nuclear Factor $\kappa \mathrm{B}$ Ligand Up-Regulation via Prostaglandin $\mathrm{E}_{2} \mathrm{Syn}_{-}$ thesis. Journal of Bone and Mineral Research: The Official Journal of the American Society for Bone and Mineral Research, 17, 210-220. http://dx.doi.org/10.1359/jbmr.2002.17.2.210

[21] Ramamurthy, N.S., Rifkin, B.R., Greenwald, R.A., Xu, J.W., Liu, Y., Turner, G., Golub, L.M. and Vernillo, A.T. (2002) Inhibition of Matrix Metalloproteinase-Mediated Periodontal Bone Loss in Rats: A Comparison of 6 Chemically Modified Tetracyclines. Journal of Periodontology, 73, 726-734. http://dx.doi.org/10.1902/jop.2002.73.7.726

[22] Wu, Y.M., Richards, D.W. and Rowe, D.J. (1999) Production of Matrix-Degrading Enzymes and Inhibition of Osteoclast-Like Cell Differentiation by Fibroblast-Like Cells from the Periodontal Ligament of Human Primary Teeth. Journal of Dental Research, 78, 681-689. http://dx.doi.org/10.1177/00220345990780020801 
Scientific Research Publishing (SCIRP) is one of the largest Open Access journal publishers. It is currently publishing more than 200 open access, online, peer-reviewed journals covering a wide range of academic disciplines. SCIRP serves the worldwide academic communities and contributes to the progress and application of science with its publication.

Other selected journals from SCIRP are listed as below. Submit your manuscript to us via either submit@scirp.org or Online Submission Portal.
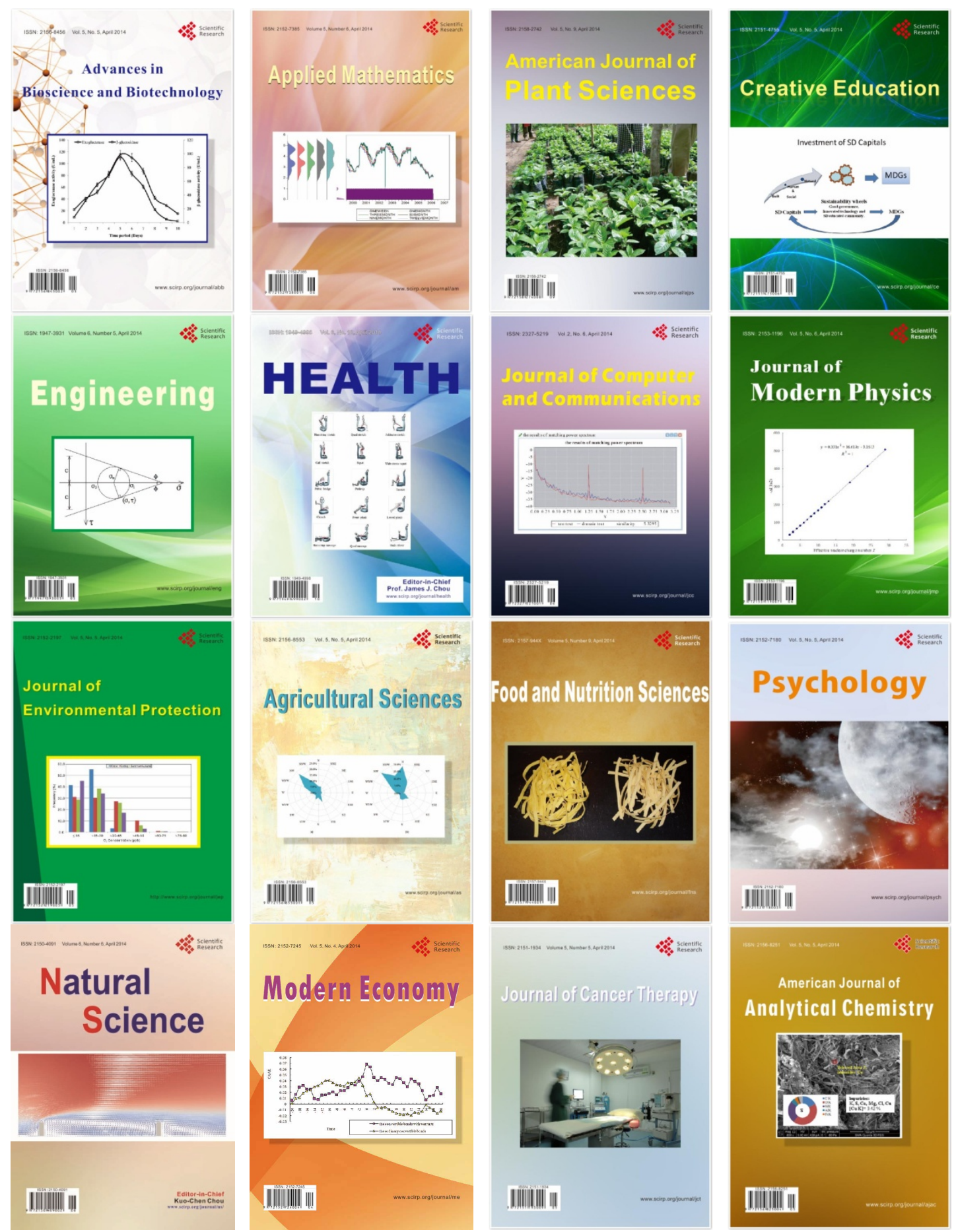